purpose, it is still of interest to compare ours with two most recent values. These are listed in Table II. In the "\% Diff." column is given the percentage difference of our reading from the other values.

Meyers and Van Dusen's readings, as well as O. C. Bridgeman's, were made with rotating piston gauges which must contend with more serious elements of uncertainty than are en- countered with an open tube mercury manometer.

The construction of this manometer was made possible by grants from the Rumford Fund of the American Academy. The long process of assembly and test has been supported by grants-inaid from the Wisconsin Alumni Research Founddation. Our thanks are tendered to both for their generous help.

\title{
LABORATORY AND SHOP NOTES
}

\section{Removal of Scratches from Photographic Film}

In reproducing cloud chamber pictures by enlarging from a $35 \mathrm{~mm}$ movie film negative we have found that small scratches on the film are very bothersome. Such scratches are almost inevitable if the negative is pulled through a projecting apparatus several times for the purpose of measuring the tracks, before an enlargement is made. We have found that even very bad scratches can be eliminated completely in the enlargement by the following procedure. The particular frame which we wish to enlarge is first clipped out of the strip. A large drop of Canada balsam is placed on each side of the film. This is then squeezed between two glass microscope slides. Care must be taken that no small air bubbles remain in the balsam. The glass slides are then bound together with ordinary gummed slide binding tape and labeled. This preserves the negative in permanent and convenient form. Since the balsam has nearly the same index of refraction as the film and the emulsion, scratches and grooves become entirely invisible, unless some silver has actually been scratched out of the emulsion.

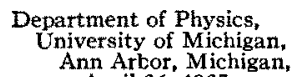

H. R. CRANE

\section{Rigid Support for Heated Filaments}

In many types of apparatus it is highly desirable to give substantial rigidity to a heated flament. This is particularly true in a mass spectrograph, where the fllament which supplies the electron beam must be maintained over its entire length in a fixed position relative to a slit, against gravitational force and the force exerted on it by the magnetic field. When the filament is heated by direct current the latter force will, in time, warp even a single strip filament.

The mass spectrograph in this laboratory is fitted with a helical filament of 6 mil tungsten wire wound on a cylinder of synthetic sapphire (corundum) $1 \mathrm{~mm}$ in diameter and $1 \mathrm{~cm}$ long. The cylinder is supported at the ends in holes drilled in the stout conductors which carry the current to the filament. This type of mounting has given no trouble over a period of several months.

The sapphire cylinder can be secured from any competent lapidary at a small cost ( $\$ 1$ in our case).

Pupin Physics Laboratories,

Columbia University,

New York City, April 17,1937 .

\section{BRIEF NOTICES OF NEW BOOKS}

Atomic Spectra and Atomic Structure. G. HerzBerg. Translation of volume published in German, 1936. Pp. $257+x i v$, Figs. $80,15 \frac{1}{2} \times 23 \frac{1}{2} \mathrm{~cm}$, Prentice-Hall, Inc., New York, 1937, Price $\$ 4.25$.

Atomic Structure of Minerals. W. L. BRAGG, Langworthy professor of physics, Victoria University, Manchester, England. Pp. $292+x i i$, Figs. 142, $15 \frac{1}{2} \times 23 \frac{1}{2} \mathrm{~cm}$. Cornell University Press, Ithaca, New York, 1937. Price $\$ 3.75$.

Introduction to Modern Thermodynamical Principles. A. R. UbBelohde. Pp. $132+$ viii, Figs. $11,14 \frac{1}{2} \times 22 \frac{1}{2} \mathrm{~cm}$. Oxford University Press, New York, 1937. Price $\$ 3.00$.
Structure of Atomic Nuclei and N uclear Transformations. G. Gamow. Second edition of Constitution of Alomic Nuclei and Radioactivity. Pp. $270+x i i$, Figs. $70,15 \frac{1}{2} \times 24$ cm. Oxford University Press, New York, 1937. Price $\$ 6.00$.

Univers Isomorphes et Constantes Physiques. L. Counson, professor, University of Lìge. Pp. $39,21 \times 27$ cm. Mimeographed. Editions E. D. K., Liège, Belgium.

Zero to Eighty. E. F. Nor THR UP (under name of $A k k a d$ Pseudoman). Pp. 239, Figs. 16+technical supplement, Pp. 41, Figs. 13, $15 \times 24 \mathrm{~cm}$. Scientific Publishing Company, Princeton, New Jersey, 1937. Price $\$ 3.00$. 